\title{
is Research Square \\ Alexithymia, Suicidal Ideation and Behaviour in Moroccan Psychoactive Substance Users
}

\section{Khadija Karjouh ( $\nabla$ khadija-pp@hotmail.com )}

Universite Ibn Tofail Kenitra https://orcid.org/0000-0002-3447-0532

\section{Fatima-Zahra Azzaoui}

Universite Ibn Tofail Kenitra Faculte des Sciences

\section{Riadh Ouerchefani}

University of Tunis El Manar: Universite de Tunis El Manar

\section{Wafae idrissi semlali}

Universite Ibn Tofail Kenitra Faculte des Sciences

Khaoula Mammad

Universite Ibn Tofail Kenitra Faculte des Sciences

\section{Ghizlane Chtabou}

Universite Ibn Tofail Kenitra Faculte des Sciences

\section{Ahmed Ahami}

Universite Ibn Tofail Kenitra Faculte des Sciences

\section{Primary research}

Keywords: Alexithymia, Suicidal ideation, suicidal behaviors, Substance abuse, Anxiety, depression

Posted Date: January 13th, 2021

DOl: https://doi.org/10.21203/rs.3.rs-143731/v1

License: (c) (i) This work is licensed under a Creative Commons Attribution 4.0 International License.

Read Full License 


\section{Abstract}

Alexithymia is an emotion regulation problem that may be related to suicidality, especially in patients with SUD.

The study aimed at estimating the prevalence of alexithymia in Moroccan psychoactive substances users, and to establish the links between alexithymia and suicidal ideation and behaviors, anxiety and depression in drug-dependent patients.

We also aimed to elucidate if alexithymia predicts suicidal thoughts and behaviors in these consumers.

The study included 451 consecutively admitted patients with substance use. Consumers were examined with the Toronto alexithymia scale (TAS-20), State and Trait Anxiety Inventory (STAI-Y), Beck Depression Inventory (BDI) and The Columbia-Suicide Severity Rating Scale (C-SSRS)

Among substance-dependent individuals, $72.7 \%$ was identified as a group with alexithymia. Current age and age at first substance use were lower in the alexithymic group $(p<0.01)$.

The mean STAI-Y state and C-SSRS scores were higher in the group with alexithymia $(p<0.01)$. There was a statistically significant difference between the groups in terms of mean scores for anxiety traits $(p<0.05)$ and no significant difference in terms of mean scores for depression. All of the scores correlated significantly with.

Addicted patients with alexithymia could be targeted at preventing the onset of suicidal thoughts and behavior

The present study also evokes that whenever an emotional regulation disorder is observed, the possibility of anxio-depressive symptomatology and suicidality (ideation and behavior) needs to be assessed.

\section{Introduction}

Alexithymia was first elucidated, by Sifneos in 1973, as a dysfunction of affective and cognitive functioning marked by incapacity to identify or express emotional experiences. It is characterized by an absence (a) of words (lexi) for feelings (thymia) to express oneself and an impairment cognitive processing of emotions, literally meaning "no words for mood" (Sifneos, 1973).

Other researchers such as Bagby and Taylor characterized patient with alexithymia as showing difficulties in identifying and describing emotions (Bagby, Taylor, et al., 1994). Among the main distinguishing features of alexithymia include: difficulty identifying feeling (DIF) and distinguishing between feelings and the bodily sensations of emotional arousal; difficulty describing feelings (DDF) to other people; constricted imaginal capacities and having an externally oriented cognitive thinking (EOT) (Taylor et al., 1997). 
A number of recent studies suggest that rates of alexithymia in general population range between $6-10 \%$ (Hintikka et al., 2001; Kokkonen et al., 2001) and it is found to be more common in men (Franz et al., 2008; Salminen et al., 1999). In clinical practice, the prevalence of alexithymia is relatively high among subjects with mental disorders (Leweke et al., 2012).

Moreover, Alexithymia has been linked to multiple psychopathologies, including depressive disorders, anxiety troubles, (especially, panic disorder ) (Hendryx et al., 1991; Parker et al., 1991), somato-form disorders, eating disorders, alcohol disorders, personality disorders and pathological gambling (Alpaslan et al., 2015; Conrad et al., 2009; Espina Eizaguirre et al., 2004; Honkalampi et al., 2000a; Marchesi and al., 2014). Other investigators have also associate the condition with Substance use disorder (Nehra et al., 2013; Torrado et al., 2013), a neuropsychiatric disorders characterized by a craving for, the development of tolerance to, and difficulties in controlling the use of a particular substance or a set of substances (a recurring desire to continue taking the drug despite harmful consequences), as well as withdrawal syndromes upon abrupt cessation of substance use. Apart from the aforementioned, it is frequently linked to other psychiatric problems such as, depressive disorder (DD), or anxiety disorder.

Epidemiological investigations regularly show an overlap between alexithymia and substance use disorders due to the high significant incidence levels of alexithymia found within drug-dependent populations ( 39\% - 50.4\%) and are remarkably consistent with each other studies (Farges, 2000; Farges et al., 2003; M. G. Haviland et al., 1988; MG. Haviland et al., 1994; Keller et al., 1995; Troisi et al., 1998), with the except for Jouanne and collaborators, who observed $69 \%$ alexithymic subjects among a sample of patients with multiple addictive behaviors, but this high prevalence should be qualified because of the small number of subjects recruited in this study (Jouanne et al., 2005). Therefore, Alexithymia appears to be commonly seen in persons with substance use disorders.

Most of these studies used the TAS-20 self-assessment and almost exclusively administer to young individuals with substance dependence.

Moreover, Farges' study confirmed elevated prevalence of alexithymia in 128 substance-dependent patients (Farges et al., 2004), though the substance has not been specified, but in a study by Parolin and colleagues (Parolin et al., 2016), the majority of patients were opioid addicted.

Addictive disorders are also associated with various psychological troubles such as sleep disorders, suicidal behavior and depressive disorders. In this line of thinking, it can be inferred that alexithymia appears to be positively associated to variables of substance use history and drug addiction, anxiety and depression.

Alexithymia is primarily seen as a relatively stable personnality trait (Primary Alexithymia $=$ neurobiological origin) (Taylor, 2000; Taylor \& Bagby, 2004), contributing to susceptibility in psychiatric problems (Mikolajczak \& Luminet, 2006), that may also be apparent even before the occurrence of mental disorders (Luminet et al., 2001, 2007). 
It reveals a dysfunction in cognitive treatment and regulation of emotions (Taylor, 2000). The condition has been thought of as a developmental dispositional factor, that occurs during childhood or early adulthood (Freyberger, 1977; Messina et al., 2014).

Some authors have hypothesized authors have hypothesized that alexithmic individuals may be submerged by unmanageable and uncontrollable emotions because of their cognitive disabilities in identifying and processing sensations and seek to treat depressive troubles or anxiety caused by alexithymia by taking drugs and alcohol (Stewart et al., 2002; Taylor et al., 1997). Consequently, these may serve as an "antidote" for alexithymia, helping patients to self-regulate these disruptive emotions and to convey through its effects sensations and emotions, that could never be transmitted without it (Taylor, 2000).

Additionally, the etiology of alexithymia also appears to be related to genetic factors (Jørgensen et al., 2007), In addition, there is evidence that certain neurobiological manifestations are associated with alexithymia (Taylor, 2000; Taylor \& Bagby, 2004).

Majority of the research in literature appear to approach alexithymia as a stable personality trait. For example, authors like (Salminen et al., 1994) suggest the continued aspect of alexithymia by highlighting both the relative and absolute stability of the traits. The authors found that there was no significant change in the mean alexithymia scores over the one-year period, whilst there was a meaningful reduction in psychological distress.

In contrast, secondary (or state) alexithymia is described as a defense mechanism, transient, state dependent phenomenon (Carano et al., 2012). The result is secondary to the occurrence of psychological distress, events and/or trauma, and which later may Calm simultaneously with mental and physical symptoms (Freyberger, 1977; Mikolajczak \& Luminet, 2006; Taylor et al., 1997).

For instance, in follow-up periods in substance-dependent group, it was found that alexithymia scores decreased with improvement in clinical symptomatology (de Haan et al., 2012). Alexithymia, can in some cases, serve as a defense mechanism in addicts who have been overwhelmed with the extreme by their painful feelings, or not feeling their emotions at all (M. G. Haviland et al., 1988; Khantzian, 1997). In such scenarios, it may help improve emotional and verbal communication and calm stressful situations in alexithymic subjects (Rybakowski et al., 1988). It is argued that, the severity of alexithymia appears related with self-perpetuating cycle of emotional disturbance and interpersonal difficulties (Cecero \& Holmstrom, 1997). In some cases and to prevent feeling an unbearable emotional state that it may develop in response to a stressful situation (Krystal, 1982; Zeitlin et al., 1993). Interestingly, some investigators assert that instances of substance abuse may help such individuals to alleviate distress or to experiencing or controlling absent or confusing emotions (Khantzian, 1997).

Thirdly, the concept of organic alexithymia relates to a state where the alexithymia is allegedly induced by organic damages to cerebral structures responsible for the processing of emotions using direct or indirect cerebral injuries (Becerra et al., 2002). It is conceptually useful to classify organic alexithymia as a 
particular subsector of secondary alexithymia resulting from a traumatic brain or vascular injuries (Messina et al., 2014), with the understanding that further outcome and treatment studies may suggest that it should be regarded as a distinct class (Huang et al., 2010).

Subsequently, different studies examining individuals with brain injury, confirmed the strong association between alexithymia and brain injury that caused damage to brain region playing a role in emotional processing and decoding emotional significance of an event (Becerra et al., 2002; Koponen et al., 2005).

Addictive disorders are already known to be characterized by the presence of depressive and anxiety symptoms.

There is a significant corpus of studies supporting the exact nature of relationship between alexithymia and psychopathology morbidity is related to depressive disorder (Haatainen et al., 2004; Hintikka et al., 2001), hence including individuals with high suicide, furthermore mediated not only especially by severity of depression (Carano et al., 2012; D. D. De Berardis et al., 2008) but also outside of these depressive symptomatology (Hintikka et al., 2004). While others suggest that it is a secondary reaction to decrease psychological and physical pain (Conrad et al., 2009; Kirsi Honkalampi, Hintikka, Tanskanen, et al., 2000; C. Marchesi et al., 2000) and that variations in alexithymia are strongly related to simultaneous variations in depression (Honkalampi et al., 2000; 2001a; 2001b).

Recently, some investigators also stated that adults with (MDD) with alexithymia have higher suicidal thought and suicide behaviors levels than non alexithymic subjects (izci et al. 2015), it can be used as a defensive operation for alcoholic individuals refusing painful effect (M.G Haviland, MacMurray, et al., 1988). However, few studies indicated that depressive symptoms are the main component for suicide attempts and not alexithymia (lancu et al., 1999; Sayar et al., 2003).

Moreover, suicidal thought in alexithymic individuals with anxiety troubles may occur in the presence of comorbid depression (Altıntaş et al., 2018).

However, recently published surveys have demonstrated that the relationship between alexithymia and suicide exists independently of depression and remains, even after accounting for it (Kim et al., 2016). Further, it was observed to be meaningfully linked to substance and alcohol consumption, suicidal ideation and behavior beyond these symptoms (Kealy et al., 2018).

Alexithymia was reported to be affecting (Posse \& Hällström, 1998), enhancing, developing, worsening and maintaining troubles (Conrad et al., 2009; Kirsi Honkalampi et al., 2010; S. Saarijärvi et al., 2006; Tolmunen et al., 2011), and it is mostly related to increased mortality risk from multiple origins (Kauhanen et al., 1996).

Various elements are linked to both alexithymic trait and suicide. These include but not limited to sociodemographic variables like gender, age, and being unmarried, as well as low socioeconomic variables (K. Honkalampi et al., 2001; Kauhanen et al., 1993; Mann, 2002). 
Therefore, it is necessary to determine the features of addicted individuals with suicidal ideation in order to prevent suicidal attempts in the future and suicide risk that represents a composite measurement of different risk factors related to individuals with suicide attempt compared to individuals without (Plutchik \& Van Praag, 1989).

In a recent review on the role of alexithymia in suicidality, Berardis reported the increase in risk with alexithymia (Domenico De Berardis, Fornaro, et al., 2017), Thus, alexithymia could be linked to suicidality/suicide attempt, which is one of the most severe consequences of depressive symptoms.

More recently, several evidences have shown that alexithymia maybe a risk factor for suicidality and auto-mutilation in subjects with conditions such as Eating Disorders (EDs) (Alpaslan et al., 2015; Carano et al., 2012), Anxiety Disorders (AD) (D. De Berardis et al., 2005; 2008; Domenico De Berardis et al., 2014, 2015; Kim et al., 2016), Affective Disorders (ADs) (Domenico De Berardis et al., 2008; Hirsch et al., 2001; Loas et al., 2016; Carlo Marchesi et al., 2014; S Saarijärvi et al., 2001; Serafini et al., 2017), schizophrenia (Marasco et al., 2011) and substance use discorder (SUD) (Evren et al., 2009; Evren \& Evren, 2005; Sakuraba et al., 2005).

Individuals with these disorders and alexithymia pointed out a greater suicidal thought compared to non alexithymics. In another perspective, the development of alexithymia was associated to an elevated suicide risk in such individuals. Thus, the assessment of alexithymia in these subjects may be specific importance and to be included like a potential risk factor.

That notwithstanding, there seems to be a controversy in the bibliography associating alexithymia and suicide ideation and behavior. The minority of the studies, but not among substance dependents, have identified no positive association between level of alexithymic traits and suicidality, specifically attempted suicides mortality or severity suicide wish (Taiminen et al., 1996; Sayar et al., 2003) and suicidal ideation (lancu et al., 1999).

Similarly, in the context of Alexithymia, Suicidal Ideation (SI) and Attempts; for Lester's study, no statistically significant differences emerged between alexithymia and $\mathrm{SI}$, among college students with suicidal behavior compared to non-suicidal students (Lester, 1991) and alexithymia was not a significant determinant of suicidality (Evren \& Evren, 2006).

Nevertheless, there was a large number of studies that discussed a positive association between alexithymia and suicide.

lancu was one of the first authors to find that elevated symptoms of alexithymia in patients with anxiety disorders were correlated with elevated suicidality although the correlations between symptoms of depression and suicide risk were the most important (Alex (SI) + Attempts) (lancu et al., 2001).

Higher rates of suicide attempts are also observed among subjects with alcohol use disorders (Rossow et al., 1999). Moreover, Suicidal behaviour is also highly reported among other substance users (Dhossche et al., 2000; Preuss et al., 2002; Roy, 2003) and suicide risk was relatively higher (5-10 times) than the 
general population (Voss et al., 2013). It has been frequently observed that the presence of uncontrollable experience of emotional distress is a predictor of suicidal ideations and behaviors (Dour et al., 2011; Shneidman, 1998).

Similarly, to alexithymic patients, substance dependents with Suicidal Ideation and behaviour may be had limited emotional and cognitive ability, unable to distinguish his feelings, communicate them and solve the problem (Orbach et al., 1990). Perhaps the suicidal individuals has inability communicating or expressing their emotions (Bear, 1998; Farber, 1997).

Regarding the association of suicide and alexithymia in psychological pathologies, this is the essence of what has been found and developed in this field.

As far as we are concerned, we are more interested in the relationship between alexithimia and the suicidality among psychoactive substance users. Sinc until now, few studies (only 8 ) have examined the interrelationships between alexithymic traits and suicidal Attempts, behaviours, Ideations and nonsuicidal self-injury (NSSI); and the results found had divergent correlations.

In a study conducted with participants with SUD, no consistent association was found between alexithymia and suicide attempt but depression was correlated with the condition (M. G. Haviland et al., 1988). Another recent studies showed no positive correlation between alexithymia and history of NSSI (Evren et al., 2009; Oyefeso et al., 2008; Verrocchio et al., 2010). Consistent with these, Sakuraba also found no difference in alexithymia between alcohol patients with high and low suicidal ideation (SI), and a higher alexithymia levels in alcoholics with high or low SI compared to controls (Sakuraba et al., 2005).

On the contrary, more recently, (Ghorbani et al., 2017) has found a positive association of alexithymia and suicidality, specifically suicidal ideation and attempts, in alcohol dependent outpatients and also high levels of alexithymia in those who have attempted suicide compared to those who have not.

Studies carried out by Evren and Evren among substance dependents patients with self-mutilation (SM) and with $(\mathrm{SAH})$, revealed that individuals with $(\mathrm{SM})$ and $(\mathrm{SAH})$ were related to alexithymia especially in relation to difficulties in identifying and describing (DIF and DDF) emotions, since no meaningful change was noted between groups regarding the EOT subscale (Evren \& Evren, 2005, 2006), and as well, the rate of SAH emotional abuse was higher in alexithymic substance dependent patients than non-alexithymic group (Evren et al., 2009).

Alexithymia was also related to self-injurious behavior (Zlotnick et al., 1996) which could elevate the capability for suicide and transit from ideation to attempt by committing to painful and/or provocative behaviors (e.g., NSSI) (Law et al., 2015). More lately, studies among substance dependents patients with (NSSI) had markedly elevated rates of alexithymia compared with those without, alexithymia score was significantly higher (Evren \& Evren, 2005), and only DIF was an important indicator of NSSI (Oyefeso et al., 2008; Verrocchio et al., 2010) and they are more likely to commit suicidal behavior if they have also committed repeated self-harm because of their difficulty regulating emotions (Law et al., 2015). 
Consequently, despite the absence of a suicide message in dependent subjects by the incapacity to express their emotions, the probability of a suicide attempt must not be played down (Sakuraba et al., 2005). Due to the importance of communicating suicidal thoughts and feelings in suicidality prevention, alexithymia features in substances users may lead to an overlooked suicidal risk.

However, researchers like (Ghorbani et al., 2017) showed the prominent relationship between DDF and EOT subscales related to current $\mathrm{SI}$, and that alcoholic individuals are characterized only by EOD in a statistical model of both SI and attempt (Ghorbani et al., 2017).

Therefore, it can be argued that the more people have alexithymia, the more likely they will show inability to develop secure social and private relationships due to their difficulty in identifying and describing and managing emotional states (Heaven et al., 2010; Rieffe et al., 2006); separation anxiety; and avoidant tendencies (Oskis et al., 2013), and they are more affected by addiction(Afshari, 2019). According to HELMERS, these individuals were those who consumed the most alcohol and/or substances (Helmers \& Mente, 1999) and had a shorter period of abstinence (Ziółkowski et al., 1995).

Finally, incoherent results between alexithymia and suicidality have been pointed out among SUD (Ghorbani et al., 2017; Sakuraba et al., 2005, Evren and Evren, 2006; Haviland et al., 1988).

Although alexithymia simply increases the risk of developing depression, there is an increasing evidence that it can be considered a risk factor for suicide (D. De Berardis et al., 2005). This evidence is based on the findings of various surveys carried out among both general population and clinical populations of individuals presenting psychiatric disorders or medical pathologies.

In summary and based on the research so far, the body of literature illustrating the role of alexithymia in suicidality, specifically suicide ideation and suicide behavior observed in patients with SUD had only limited attention and infrequently evaluated. The lack of research exploring this link reflects an important deficiency in the literature given the possible implication of the alexithymia. This could, therefore, constitute a field of vulnerability, or even be a risk factor for suicide among this population. Nevertheless, results of these few studies which examined the associations between alexithymia and suicidality, differ depending on the focus of the study on suicidal ideation, suicide attempts, or NSSI. It is therefore important to explore the link between alexithymia and suicide by examining specifically the correlations of suicidal ideation and behavior simultaneously and separately.

Since suicidal behaviors suggest a variety of causes, it is important to define what emotional capacities are associated with in managing emotions. Although there is no effective predictive model for suicide in clinical practice, a better recognition and understanding of emotional abilities may help in identifying high-risk individuals and selecting treatment.

In the multifactorial causality of SUD, it is not clear yet if individuals with SUD who also have alexithymic features have an elevated suicidal risk. We hypothesize that the availability of alexithymia may enhance the suicide risk in addicted patients. Consequently, the aim of the present research was to assess the 
frequency of alexithymia in a sample recruited at the centre and then examines the links between alexithymia and suicidal ideation and behaviors among addicted patients. We hope to examine the relation between alexithymia, depression, anxiety trait and state and suicide probability among drug dependent patients. We also aimed to establish whether alexithymia is a determinant of suicidal ideation and behaviour among these consumers.

\section{Methods}

\section{Subjects}

The study was conducted during one year, from March13st, 2017 to March 30rd, 2018.

The participants consisted of 451 patients, 62 (13.7\%) women and $389(86.3 \%)$ men, who were received at the centre for the first time.

The recruitment of patients is based on the following criteria: the patients not having undergone any treatment recently.

Patients were included if they satisfied criteria for a current SUD other than nicotine.

Interviews with the individuals that computed the study sample were done after accepting the patient at the centre.

\section{Measures}

All the patients were evaluated through the use of a semi-structured socio-demographic information form, this form included questions on age, sex, marital/ professional and academic status...

The following questionnaires were subsequently given to the participant. The features of the measurements involved in this survey may be synthesized as follows:

The 20-item Toronto Alexithymia Scale (TAS-20) is actually the most commonly used measurement of alexithymia(Bagby, Parker, et al., 1994; Bagby, Taylor, et al., 1994).

This scale was applied to investigate the level of alexithymia (Parker et al., 1993) ,alexithymia defined as not recognizing one's own feelings and excitement. The TAS-20 is a self-report scale made of 20 items that must be rated from 1 (strongly disagree) to 5 (strongly agree). The overall score varies from 20 to 100 with higher scores indicate more severe alexithymia. The total of the items results in a sum score and scores for three subscales; the mesure has a three- interdependent factor solution: difficulty identifying feelings (DIF) (F1), difficulty describing feelings (DDF) (F2), and externally oriented thinking (EOT) (F3) subscales (Bagby, Parker, et al., 1994; Bagby, Taylor, et al., 1994).

The scale was assessed as a valid and reliable measurement in both clinical and non-clinical populations (Bagby, Parker, et al., 1994; Bagby, Taylor, et al., 1994; Bressi et al., 1996; Parker et al., 1993; Taylor et al., 
2003).

\section{The State and Trait Anxiety Inventory (STAI-Y):}

This self-report measure that quantifies anxiety, it is administered to patients over the age of 14.This special measure serves to simplify the distinction between state anxiety and trait anxiety, the anxiety feeling and depressive symptoms. STAI-A evaluates state while STAI-B measures trait anxiety (Spielberger, 1993). The STAI consists of 40 items requiring around 10-20 minutes to answer and the test is administered in dozens of foreign languages worldwide. This test is divided into two scales: the SAnxiety scale and the T-Anxiety scale, each consisting 20 items. Answers to these tests are given on a scale of 1 to 4 scale, with the following areas listing: worry, tension, apprehension, and nervousness (Spielberger et al., 1970).

Beck Depression Inventory (BDI) 21-item: This self-report scale was developed by Beck in order to evaluate the level and severity of the cognitive, affective, and somatic symptoms of depressive disorders and has been used in studies on mental health troubles. The questions include 4 ordinal classes (from 0 through 3). Absence of depression symptom in each item is rated as "0" and existence of symptom is rated between 1 and 3 , with the greater score signifying higher levels symptom severity. The potential total score is between 0 and 63.(A. T. Beck et al., 1961; Aaron T. Beck et al., 1988).

The Columbia-Suicide Severity Rating Scale (C-SSRS) (Posner et al., 2011) is a semistructured interview how was developed to fill a void, where there was no unique assess that included systematic measure of both suicide thought (passive and active suicidal ideation) and behaviour (i.e., actual attempts, interrupted attempts, aborted attempts, preparatory acts or behaviour, and self-injurious behaviour), to quantify the severity of suicidal ideation, the intensity of ideation, suicidal behaviour, and lethality of suicide attempts.

I have received training in administration of this scale. The use of this questionnaire requires training.

Statistical analyses were conducted with the SPSS statistical software package (25) for Windows, for all the analyses.

\section{Results}

Sociodemographic features of the sample and SPAs use are summarized in Table 1. 
Table 1

Socio-demographic variables of addicted patients and SPA use:

\begin{tabular}{|c|c|c|}
\hline \multicolumn{2}{|c|}{ Socio-demographic characteristics } & \multirow{2}{*}{$\begin{array}{l}\text { Percentage (\%) } \\
86,3\end{array}$} \\
\hline Gender & Male & \\
\hline & Female & 13.7 \\
\hline \multirow[t]{6}{*}{ Age Range (years) } & 10_20 & 38 \\
\hline & $20-30$ & 34 \\
\hline & $30-40$ & 17 \\
\hline & $40-50$ & 7 \\
\hline & $50-60$ & 3 \\
\hline & $60-70$ & 1 \\
\hline \multirow[t]{5}{*}{ School levels } & Illiterate & 4 \\
\hline & Primary & 13 \\
\hline & Middle school & 38 \\
\hline & High School & 29 \\
\hline & University and above & 16 \\
\hline \multirow[t]{4}{*}{ Marital status } & Single & $77 \%$ \\
\hline & Married & $17 \%$ \\
\hline & Divorced & $5 \%$ \\
\hline & Separated/ Widowed & $1 \%$ \\
\hline Age at onset (years) & $(5-10]$ & 4 \\
\hline \multirow[t]{3}{*}{ Age at first substance use } & $(10-15]$ & 56 \\
\hline & $(15-20]$ & 33 \\
\hline & $(20-30]$ & 5 \\
\hline \multirow[t]{2}{*}{ Diploma } & Yes & 37 \\
\hline & No & 63 \\
\hline
\end{tabular}

"maâjoun": Moroccan preparation, a pasty electuary prepared from cannabis resin and a number of aphrodisiac substances.

"Kif": a blend of tobacco and Indian cannabis in North Africa.

"Kala": a mixture of tobacco powder that users roll in a leaf and place against the gingiva. 
Socio-demographic characteristics

\begin{tabular}{|lll}
\hline Employment status & Employed & $43 \%$ \\
& Unemployed & $57 \%$ \\
\hline Psychoactive substance use & Tobacco (snuff tobacco) & $76 \%$ \\
& Cannabis & $86 \%$ \\
& Alcool & $53 \%$ \\
& Benzodiazepines & $40 \%$ \\
Maajun & $24 \%$ \\
& Ecstasy & $11 \%$ \\
& kala & $9 \%$ \\
& solvent & $10 \%$ \\
Kif & smoking hookah & $4 \%$ \\
& Cocaine & $3 \%$ \\
Heroin & $9 \%$ \\
& & $1 \%$
\end{tabular}

"maâjoun": Moroccan preparation, a pasty electuary prepared from cannabis resin and a number of aphrodisiac substances.

"Kif": a blend of tobacco and Indian cannabis in North Africa.

"Kala": a mixture of tobacco powder that users roll in a leaf and place against the gingiva.

Out of the 451 drug abusers who participated in the study, about $38 \%$ of participants were from middle school; while, $29 \%$ were from high school, $16 \%$ were from University and above, $13 \%$ were from Primary and only $4 \%$ were Illiterate and $30 \%$ of them received a diploma. Among the sample $86.3 \%(n=389)$ of the participants were male and $13.7 \%(n=62)$ were female. Concerning the age groups, nearly $72 \%$ of participants were the age between $10-30$ years, the mean age was 26,94420 years (SD \pm 2 years); regarding age at onset of drug use, the most of abusers (60\%) were aged between 5 and 15 years at first substance use. As shown in Table 1, $57 \%$ of surveyed drug abusers were unemployed and $43 \%$ employed. Regarding marital status, the majority of patients were single (77\%).

Cannabis recorded the highest prevalence with $86 \%$, followed by tobacco (76\%), alcohol (53\%), psychotropic substances without medical prescription (40\%), maajoun (24\%), amphetamine "Extasy" (11\%), "Kala" (9\%), inhalants (10\%), smoking hookah (3\%), cocaine (9\%), heroin (1\%).

In general, the rate of poly drug use (two or more PASs) was $81 \%$. 
Alexithymic and non-alexitymic participants were evaluated according to the age, age at onset, BDI, STAI$Y$ and C-SSRS scores. The mean age and age at onset in the alexithymic group were 26,32 $\pm 10,039$ and $14,99 \pm 3,469$, respectively. The mean age and age at onset in the non-alexithymic group were $27,99 \pm$ 11,756 and $15,84 \pm 4,953$, respectively. So, mean age and age at onset were more elevated in the nonalexithymic dependent group $(p<0.01)$.

There was no statistically significant difference between the groups in terms of age $(p>0.05)$ while there was a significant difference of age at onset $(p<0.01)$.

The mean STAI-Y State (trait) and C-SSRS ideation (behaviors) ratings in the alexithymic participants were 49,83 $\pm 8,607(49,68 \pm 9,396)$ and 1,91 $\pm 1,985(1,25 \pm 1,717)$, respectively. The mean STAI-Y State (trait) and C-SSRS ideation (behaviors) scores in the non-alexithymic participants were 47,75 $\pm 8,799$ $(46,28 \pm 11,020)$ and $1,04 \pm 1,608(0,58 \pm 1,239)$, respectively.

So, mean the mean STAI-Y state and C-SSRS scores were higher in the alexithymic patients $(p<0.01)$.

There was statistically significant difference between the groups according to anxiety trait mean scores $(p<0.05)$ (Table 2). 
Table 2

\begin{tabular}{|c|c|c|c|c|}
\hline & $\begin{array}{l}\text { Alexithymic } \\
(n=328,72.7 \%)\end{array}$ & $\begin{array}{l}\text { Non Alexithymic } \\
(n=123,27.3 \%)\end{array}$ & $t$ & $\mathbf{P}$ \\
\hline $\begin{array}{l}\text { Age } \\
(\text { mean } \pm S D)\end{array}$ & $26,32 \pm 10,039$ & $27,99 \pm 11,756$ & 3,588 & 0,059 \\
\hline $\begin{array}{l}\text { Age at onset } \\
\text { (mean } \pm S D)\end{array}$ & $14,99 \pm 3,469$ & $15,84 \pm 4,953$ & 10,191 & $0,002^{*}$ \\
\hline $\begin{array}{l}\text { Depression } \\
(\text { mean } \pm S D)\end{array}$ & $27,42(8,936)$ & $22,20(9,311)$ & 0,126 & 0,722 \\
\hline $\begin{array}{l}\text { Anxiety State } \\
(\text { mean } \pm S D)\end{array}$ & $49,83 \pm 8,607$ & $47,75 \pm 8,799$ & 0,285 & 0,594 \\
\hline $\begin{array}{l}\text { Anxiety Trait } \\
(\text { mean } \pm S D)\end{array}$ & $49,68 \pm 9,396$ & $46,28 \pm 11,020$ & 4,497 & 0,035 \\
\hline $\begin{array}{l}\text { Suicidal Ideation } \\
(\text { mean } \pm S D)\end{array}$ & $1,91 \pm 1,985$ & $1,04 \pm 1,608$ & 21,154 & $0,000 *$ \\
\hline $\begin{array}{l}\text { Suicidal Behaviour } \\
\text { (mean } \pm S D)\end{array}$ & $1,25 \pm 1,717$ & $0,58 \pm 1,239$ & 30,323 & $0,000 *$ \\
\hline
\end{tabular}

There was no statistically significant difference between the groups in terms of depression mean scores $(p>0.05)$ (Table 2).

The correlation coefficients between the total scores of the four scales, the age and the age at onset, and the corresponding P-values, are summarized in Table 3.

Table 3: Correlations between clinical scales 


$\begin{array}{cccccccc}\text { Age } & \begin{array}{c}\text { Age at } \\ \text { onset }\end{array} & \text { BDI } & \text { TAS20 } & \text { AS } & \text { AT } & \text { SI } & \text { SB }\end{array}$

\begin{tabular}{|c|c|c|c|c|c|c|c|c|}
\hline \multirow[t]{2}{*}{ Age } & 1,0000 & & & & & & & \\
\hline & $\mathrm{p}=\ldots$ & & & & & & & \\
\hline \multirow{2}{*}{$\begin{array}{l}\text { Age at } \\
\text { onset }\end{array}$} &, 2254 & 1,0000 & & & & & & \\
\hline & $\mathrm{p}=, 000$ & $\mathrm{p}=\ldots$ & & & & & & \\
\hline \multirow[t]{2}{*}{ BDI } &, 1621 &,- 0486 & 1,0000 & & & & & \\
\hline & $\mathrm{p}=, 001$ & $\mathrm{p}=, 305$ & $p=\ldots$ & & & & & \\
\hline \multirow[t]{2}{*}{ TAS 20} &,- 0050 &,- 1158 &, 2907 & 1,0000 & & & & \\
\hline & $\mathrm{p}=, 915$ & $\mathrm{p}=, 014$ & $\mathrm{p}=, 000$ & $\mathrm{p}=\ldots$ & & & & \\
\hline \multirow[t]{2}{*}{ A S } & ,1023 &,- 0129 & ,3909 &, 1258 & 1,0000 & & & \\
\hline & $\mathrm{p}=, 031$ & $\mathrm{p}=, 786$ & $\mathrm{p}=, 000$ & $\mathrm{p}=, 008$ & $\mathrm{p}=\ldots$ & & & \\
\hline \multirow[t]{2}{*}{$\mathrm{AT}$} &, 0790 &,- 0161 & ,4008 &, 1454 &, 7274 & 1,0000 & & \\
\hline & $\mathrm{p}=, 095$ & $\mathrm{p}=, 734$ & $\mathrm{p}=, 000$ & $\mathrm{p}=, 002$ & $\mathrm{p}=0,00$ & $p=\ldots$ & & \\
\hline \multirow[t]{2}{*}{ SI } &, 0449 &, 0589 &, 3782 &, 2372 &, 2386 &, 2692 & 1,0000 & \\
\hline & $\mathrm{p}=, 344$ & $\mathrm{p}=, 215$ & $\mathrm{p}=, 000$ & $\mathrm{p}=, 000$ & $\mathrm{p}=, 000$ & $\mathrm{p}=, 000$ & $\mathrm{p}=\ldots$ & \\
\hline \multirow[t]{2}{*}{ SB } &, 0422 &,- 0234 &, 2910 & ,2032 & ,1900 &, 2283 &, 8064 & 1,0000 \\
\hline & $\mathrm{p}=, 374$ & $\mathrm{p}=, 622$ & $\mathrm{p}=, 000$ & $\mathrm{p}=, 000$ & $\mathrm{p}=, 000$ & $\mathrm{p}=, 000$ & $\mathrm{p}=0,00$ & $\mathrm{p}=\ldots$ \\
\hline
\end{tabular}

Marked correlations are significant at $p<, 05000 \mathrm{~N}=451$

According to correlation analysis of age, age at onset, TAS-20 total and STAI-Y State and trait; C-SSRS ideation and behaviours, age correlated significantly with age at onset, strength of depression (BDI) and Anxiety state in PASs abusers; and it were correlated with neither the severity of alexithymia nor the anxiety trait nor the severity of suicidal ideations and behaviours $(r=0.2254, p<0.001 ; r=0.1621 ; p<0.05$ $; r=0,1023, p<0,05$; respectively), while a negative correlation was found between age at onset scores and the severity of alexithymia $(r=-0,1158, p<0.05)$. There was a positive correlation between BDI scores and TAS-20, STAI-Y and C-SSRS scores $(p<0.001)$. There was a positive correlation between TAS-20 total scores and STAI-Y and C-SSRS scores $(p<0.05 ; p<0.001)$. Also a positive correlation was found between STAI-Y scores and C-SSRS scores $(p<0.001)($ Table 3$)$.

All of the scores correlated significantly with (Table 3, partial correlations not shown).

\section{Discussion}

The present study is the first survey focusing on psychoactive substances use (PASU) among abusers in Rabat, Morocco. 
Drug addiction is a disease with profound emotional ramifications and dimensions affecting ideations, mental and somatic perceptions. Drug addiction is more frequent in alexithymic individuals with more severe bodily perceptions. Substance abuse is recognized to produce more readily in alexithymic individuals but the influence of this depressive disorder on suicidal ideation and behaviour is not well comprehended in our context.

In this centre, cross-sectional study evaluating the role of alexithymia in suicidality among PAS abusers; subjectively reported suicidal ideation was highest in male patients followed by female's. Rates of alexithymia according to established cut-offs for TAS-20 were similar for male and female groups. Zeroorder correlations revealed that TAS scores correlated significantly with various measures. Results showed that for our population, alexithymia predicted subjectively reported suicide (ideation and behaviour) and via anxious and depressive symptoms.

The previously found significant relationship between depression and alexithymia (Simo Saarijärvi et al., 1993) was supported in the current research, and it seems that inability in recognizing emotions, especially, are strongly associated with depression.

Patients with depression are at much greater risk of somatic symptoms than individuals without depression (Lipowski, 1990) anxiety, somatosensory amplification and alexithymia are the three predictors of somatization symptoms in depression (Sayar et al., 2003).

The majority of the studies supported the part played by alexithymia in activating suicidal ideations and behaviours in general population, generalized anxiety, obsessive compulsive disorder, alcoholism, eating disorders, and depression; although controversies on the exact nature of relationships between those constructs remain (Domenico De Berardis, Serroni, et al., 2017; Lecrubier, 1998; Sakuraba et al., 2005).

However, in Taiminen's study, a relationship was established between depressive symptoms and alexithymia rates, although no association was observed between alexithymia and suicidal ideation or suicide attempt. It was also observed that alexithymia was not a determinant factor of suicidal attempt in patients when compared to individuals without suicidal attempt (Taiminen et al., 1996). In this current research; the group of substance abusers with positive alexithymia have elevated rates of depression, anxiety (state and trait) and suicide ideation and behaviour so that alexithymia could contribute to their development in PAS abusers with suicidal ideation and behaviour.

The role of alexithymia in suicidality observed among PAS patients is totally neglected in our Country and our study is the first one to evaluate this constructs in Morocco. In studies conducted using TAS-20 with established cut-offs, rates for alexithymia were reported to vary between $30-78 \%$ in drug addicts (Rybakowski et al., 1988; Troisi et al., 1998). In our study, suicide thought, suicidal behaviour and depression and anxiety rates were significantly elevated among substance-abusers with alexithymia than substance-abusers without alexithymia (72.7\% dependent individuals with alexithymia and $27.3 \%$ of dependent individuals without alexithymia). These results are in accordance with the findings of other research in the literature. 
In addition, in a survey assessing alexithymia intensity, suicide ideation and depression symptoms in a general population, alexithymia measure was observed to be linked to suicide ideation intensity (Hintikka et al., 2004).

Since our study found a significant positive association between TAS scores and STAY and C-SSRS scores, it led us to believe that suicide thought and behaviour and anxiety intensity are likely to be elevated in substance-dependent depressed individuals with alexithymia who has difficulty in recognizing, describing and communicating emotions.

In several studies evaluated on various populations the contribution of alexithymia in suicidality and suggested that difficulties in recognizing and describing emotions may be related with both depression and suicide.(D De Berardis et al., 2013; Goerlich-Dobre et al., 2015; Sayar et al., 2003).

PAS abusers with positive alexithymia who has difficulty in identifying their feelings and somatic symptoms are more likely to suffer from increased levels of suicidal ideation and behaviour rates associated with anxiety features and depression.

In line with those views, TAS20 correlated with suicide ideation and behaviour scores among our patients. Our findings support the importance of all depressive and anxious symptoms and alexithymia in suicide for PAS abusers. Those results should be replicated with further studies.

Our study has some limitations. Firstly, this is a single center study conducted on clinical samples and the results may not be generalized to other centers and to the community. Secondly, our study was crosssectional and used some auto-evaluation measures for depressive and anxious symptoms and there were some confusions concerning if the participants comprehended the measures and responded to them objectively or not. Thirdly, confusion about the precision with which TAS scale measured the level of such a large phenomenon as alexithymia may be seen a further limitation. Fourth, the survey population was designed with inclusion and exclusion criteria in a way that it cannot be extended to the general public.

Finally, in this preliminary researh, we report on the role of three features in suicidality and alexithymia. Our results support the hypothesis that these features might prove to be sensitive predictors of suicidality.

In our investigation, suicidal thought, suicidal behaviour, depression and anxiety intensity were considerably more severe in substance abusers participants with alexithymia than substance abusers individuals without alexithymia. These findings appear to suggest that patients with alexithymia who have a limited conception of physical health may recognize suicidal thoughts and behaviour as corporal symptoms.

In view of our findings we can recommend that alexithymia in general could be a main result measurement for the evaluation therapeutic approaches among addicted patients which tend to decrease the risk of suicidal ideation and behaviour by enhancing emotional awareness. 
To conclude, it appears that alexithymia might be a supposed predisposing determinant for suicidality in individuals with SUD, although more prospective studies are required to prove this relationship.

\section{Declarations}

\section{Ethics approval and consent to participate}

The study was approved by the Ethics Committee of the Ibn Tofail University. All participants gave a written informed consent.

\section{Consent for publication}

Not applicable.

\section{Competing interests}

Authors report no conflicts of interest.

\section{Funding}

Not applicable.

\section{Authors' contributions}

$\mathrm{KK}, \mathrm{AA}, \mathrm{AFZ}$ and OR designed the study. KK, ISW and CG conducted the neuropsychological tests and managed the literature searches for the manuscript. KK and MK undertook the statistical analysis. KK, AA, AFZ and OR wrote the first draft of the manuscript. All authors read and approved the final manuscript.

\section{Acknowledgements}

We thank all the personnel as well as the patients of the addictology center in Rabat.

\section{References}

1. Afshari, A. (2019). Compare Alexithymia and Emotional Intelligence among Drug Users, People at Risk of Addiction and Non Drug Users. 6.

2. Alpaslan, A. H., Soylu, N., Avci, K., Coşkun, K. Ş., Kocak, U., \& Taş, H. U. (2015). Disordered eating attitudes, alexithymia and suicide probability among Turkish high school girls. Psychiatry Research, 226(1), 224-229. https://doi.org/10.1016/j.psychres.2014.12.052

3. Altıntaş, E., Kütük, M., Tufan, A., \& Bağ, H. (2018). Alexithymia is not a good predictor of suicidal ideation in patients with social anxiety disorder. Anatolian Journal of Psychiatry, 0, 577. https://doi.org/10.5455/apd.290463

4. Bagby, Parker, \& Taylor. (1994). The twenty-item Toronto Alexithymia scale-I. Item selection and cross-validation of the factor structure. Journal of Psychosomatic Research, 38(1), 23-32. 
https://doi.org/10.1016/0022-3999(94)90005-1

5. Bagby, Taylor, \& Parker. (1994). The Twenty-item Toronto Alexithymia Scale-II. Convergent, discriminant, and concurrent validity. Journal of Psychosomatic Research, 38(1), 33-40.

6. Bear, Z. (1998). Good Practice in Counselling People who Have Been Abused. Jessica Kingsley Publishers.

7. Becerra, R., Amos, A., \& Jongenelis, S. (2002). Organic alexithymia: A study of acquired emotional blindness. Brain Injury, 16(7), 633-645. https://doi.org/10.1080/02699050110119817

8. Beck, A. T., Ward, C. H., Mendelson, M., Mock, J., \& Erbaugh, J. (1961). An inventory for measuring depression. Archives of General Psychiatry, 4, 561-571.

9. Beck, Aaron T., Steer, R. A., \& Carbin, M. G. (1988). Psychometric properties of the Beck Depression Inventory: Twenty-five years of evaluation. Clinical Psychology Review, 8(1), 77-100. https://doi.org/10.1016/0272-7358(88)90050-5

10. Bressi, C., Taylor, G., Parker, J., Bressi, S., Brambilla, V., Aguglia, E., Allegranti, I., Bongiorno, A., Giberti, F., Bucca, M., Todarello, O., Callegari, C., Vender, S., Gala, C., \& Invernizzi, G. (1996). Cross validation of the factor structure of the 20-item Toronto Alexithymia Scale: An Italian multicenter study. Journal of Psychosomatic Research, 41(6), 551-559.

11. Carano, A., De Berardis, D., Campanella, D., Serroni, N., Ferri, F., Di lorio, G., Acciavatti, T., Mancini, L., Mariani, G., Martinotti, G., Moschetta, F. S., \& Di Giannantonio, M. (2012). Alexithymia and suicide ideation in a sample of patients with binge eating disorder. Journal of Psychiatric Practice, 18(1), 511. https://doi.org/10.1097/01.pra.0000410982.08229.99

12. Cecero, J. J., \& Holmstrom, R. W. (1997). Alexithymia and affect pathology among adult male alcoholics. Journal of Clinical Psychology, 53(3), 201-208. https://doi.org/10.1002/(SICl)10974679(199704)53:3<201::AID-JCLP2>3.0.CO;2-U

13. Conrad, R., Wegener, I., Imbierowicz, K., Liedtke, R., \& Geiser, F. (2009). Alexithymia, temperament and character as predictors of psychopathology in patients with major depression. Psychiatry Research, 165(1), 137-144. https://doi.org/10.1016/j.psychres.2007.10.013

14. De Berardis, D., Campanella, D., Gambi, F., Sepede, G., Salini, G., Carano, A., La Rovere, R., Pelusi, L., Penna, L., Cicconetti, A., Cotellessa, C., Salerno, R. M., \& Ferro, F. M. (2005). Insight and alexithymia in adult outpatients with obsessive-compulsive disorder. European Archives of Psychiatry and Clinical Neuroscience, 255(5), 350-358. https://doi.org/10.1007/s00406-005-0573-y

15. De Berardis, D, Campanella, D., Serroni, N., Moschetta, F. S., Di, F. E., Conti, C., Carano, A., Acciavatti, T., Di, G. I., Martinotti, G., Siracusano, A., \& Di, M. G. (2013). Alexithymia, suicide risk and serum lipid levels among adult outpatients with panic disorder. Comprehensive Psychiatry, 54(5), 517-522. https://doi.org/10.1016/j.comppsych.2012.12.013

16. De Berardis, D. D., Serroni, N., Campanella, D., Carano, A., Caltabiano, M., Pizzorno, A. M., Valchera, A., Tancredi, L., Sepede, G., \& Gambi, F. (2008). Suicide risk among patients with obsessive-compulsive disorder: The role of alexithymia and insight. Official Journal of the Italian Society of 
Psychopathology, 14. https://www.jpsychopathol.it/article/suicide-risk-among-patients-withobsessive-compulsive-disorder-the-role-of-alexithymia-and-insight/

17. De Berardis, Domenico, Serroni, N., Campanella, D., Carano, A., Gambi, F., Valchera, A., Conti, C., Sepede, G., Scali, M., Fulcheri, M., Salerno, R. M., \& Ferro, F. M. (2008). Alexithymia and its relationships with $\mathrm{C}$-reactive protein and serum lipid levels among drug naïve adult outpatients with major depression. Progress in Neuro-Psychopharmacology and Biological Psychiatry, 32(8), 19821986. https://doi.org/10.1016/j.pnpbp.2008.09.022

18. De Berardis, Domenico, Serroni, N., Campanella, D., Marini, S., Rapini, G., Valchera, A., lasevoli, F., Mazza, M., Fornaro, M., Perna, G., Di lorio, G., Martinotti, G., \& Di Giannantonio, M. (2017). Alexithymia, Suicide Ideation, C-Reactive Protein, and Serum Lipid Levels Among Outpatients with Generalized Anxiety Disorder. Archives of Suicide Research: Official Journal of the International Academy for Suicide Research, 21(1), 100-112. https://doi.org/10.1080/13811118.2015.1004485

19. De Berardis, Domenico, Serroni, N., Campanella, D., Rapini, G., Olivieri, L., Feliziani, B., Carano, A., Valchera, A., lasevoli, F., Tomasetti, C., Mazza, M., Fornaro, M., Perna, G., Di Nicola, M., Martinotti, G., \& Di Giannantonio, M. (2015). Alexithymia, responsibility attitudes and suicide ideation among outpatients with obsessive-compulsive disorder: An exploratory study. Comprehensive Psychiatry, 58, 82-87. https://doi.org/10.1016/j.comppsych.2014.12.016

20. De Berardis, Domenico, Serroni, N., Marini, S., Rapini, G., Carano, A., Valchera, A., lasevoli, F., Mazza, M., Signorelli, M., Aguglia, E., Perna, G., Martinotti, G., Varasano, P. A., Pressanti, G. L., \& Di Giannantonio, M. (2014). Alexithymia, suicidal ideation, and serum lipid levels among drug-naïve outpatients with obsessive-compulsive disorder. Revista Brasileira de Psiquiatria, 36(2), 125-130. https://doi.org/10.1590/1516-4446-2013-1189

21. de Haan, H., Joosten, E., Wijdeveld, T., Boswinkel, P., van der Palen, J., \& De Jong, C. (2012). Alexithymia is not a stable personality trait in patients with substance use disorders. Psychiatry Research, 198(1), 123-129. https://doi.org/10.1016/j.psychres.2011.09.027

22. Dhossche, D. M., Meloukheia, A. M., \& Chakravorty, S. (2000). The association of suicide attempts and comorbid depression and substance abuse in psychiatric consultation patients. General Hospital Psychiatry, 22(4), 281-288. https://doi.org/10.1016/S0163-8343(00)00085-2

23. Espina Eizaguirre, A., Ortego Saenz de Cabezón, A., Ochoa de Alda, I., Joaristi Olariaga, L., \& Juaniz, M. (2004). Alexithymia and its relationships with anxiety and depression in eating disorders. Personality and Individual Differences, 36(2), 321-331. https://doi.org/10.1016/S01918869(03)00099-0

24. Evren, C., \& Evren, B. (2005). Self-mutilation in substance-dependent patients and relationship with childhood abuse and neglect, alexithymia and temperament and character dimensions of personality. Drug and Alcohol Dependence, 80(1), 15-22. https://doi.org/10.1016/j.drugalcdep.2005.03.017

25. Evren, C., \& Evren, B. (2006). The relationship of suicide attempt history with childhood abuse and neglect, alexithymia and temperament and character dimensions of personality in substance 
dependents. Nordic Journal of Psychiatry, 60(4), 263-269.

https://doi.org/10.1080/08039480600790051

26. Evren, C., Evren, B., Dalbudak, E., Ozcelik, B., \& Oncu, F. (2009). Childhood abuse and neglect as a risk factor for alexithymia in adult male substance dependent inpatients. Journal of Psychoactive Drugs, 41(1), 85-92. https://doi.org/10.1080/02791072.2009.10400677

27. Farber, S. K. (1997). SELF-MEDICATION, TRAUMATIC REENACTMENT, AND SOMATIC EXPRESSION IN BULIMIC AND SELF-MUTILATING BEHAVIOR. Clinical Social Work Journal, 25(1), 87-106. https://doi.org/10.1023/A:1025785911606

28. Farges, F. (2000). Dépendance, abus, usage. In Toxicomanies (Masson, pp. 16-22).

29. Farges, F., Corcos, M., Loas, G., Perez-Diaz, P., Speranza, M., Guilbaud, O., Taïeb, O., Dugré-Le Bigre, C., \& Jeammet, P. (2003). Alexithymie et dépression dans la toxicomanie. In Les conduites de dépendance.Dimensions psychopathologiques communes (pp. 192-199). Masson.

30. Farges, F., Corcos, M., Speranza, M., Loas, G., Perez-Diaz, F., Venisse, J.-L., Lang, F., Bizouard, P., Halfon, O., Flament, M., \& Jeammet, Ph. (2004). Alexithymie et toxicomanie: Lien avec la dépression. L'Encéphale, 30(3), 201-211. https://doi.org/10.1016/S0013-7006(04)95431-0

31. Franz, M., Popp, K., Schaefer, R., Sitte, W., Schneider, C., Hardt, J., Decker, O., \& Braehler, E. (2008). Alexithymia in the German general population. Social Psychiatry and Psychiatric Epidemiology, 43(1), 54-62. https://doi.org/10.1007/s00127-007-0265-1

32. Freyberger, H. (1977). Supportive Psychotherapeutic Techniques in Primary and Secondary Alexithymia. Psychotherapy and Psychosomatics, 28(1-4), 337-345. https://doi.org/10.1159/000287080

33. Ghorbani, F., Khosravani, V., Sharifi Bastan, F., \& Jamaati Ardakani, R. (2017). The alexithymia, emotion regulation, emotion regulation difficulties, positive and negative affects, and suicidal risk in alcohol-dependent outpatients. Psychiatry Research, 252, 223-230. https://doi.org/10.1016/j.psychres.2017.03.005

34. Goerlich-Dobre, K. S., Votinov, M., Habel, U., Pripfl, J., \& Lamm, C. (2015). Neuroanatomical profiles of alexithymia dimensions and subtypes. Human Brain Mapping, 36(10), 3805-3818. https://doi.org/10.1002/hbm.22879

35. Haatainen, K., Tanskanen, A., Kylmaä, J., Honkalampi, K., Koivumaa-Honkanen, H., Hintikka, J., \& Viinamaki, H. (2004). Ftors Associated with Hopelessness: A Population Study. International Journal of Social Psychiatry, 50(2), 142-152. https://doi.org/10.1177/0020764004040961

36. Haviland, Mark G., Hendryx, M. S., Shaw, D. G., \& Henry, J. P. (1994). Alexithymia in women and men hospitalized for psychoactive substance dependence. Comprehensive Psychiatry, 35(2), 124-128. https://doi.org/10.1016/0010-440X(94)90056-N

37. Haviland, M.G, Shaw, D. G., MacMurray, J. P., \& Cummings, M. A. (1988). Validation of the Toronto Alexithymia Scale with substance abusers. Psychotherapy and Psychosomatics, 50(2), 81-87. https://doi.org/10.1159/000288104 
38. Heaven, P. C. L., Ciarrochi, J., \& Hurrell, K. (2010). The distinctiveness and utility of a brief measure of alexithymia for adolescents. Personality and Individual Differences, 49(3), 222-227. https://doi.org/10.1016/j.paid.2010.03.039

39. Hendryx, M. S., Haviland, M. G., \& Shaw, D. G. (1991). Dimensions of alexithymia and their relationships to anxiety and depression. Journal of Personality Assessment, 56(2), 227-237. https://doi.org/10.1207/s15327752jpa5602_4

40. Henry, J. D., Bailey, P. E., von Hippel, C., Rendell, P. G., \& Lane, A. (2010). Alexithymia in schizophrenia. Journal of Clinical and Experimental Neuropsychology, 32(8), 890-897. https://doi.org/10.1080/13803391003596462

41. Hintikka, J., Honkalampi, K., Koivumaa-Honkanen, H., Antikainen, R., Tanskanen, A., Haatainen, K., \& Viinamäki, H. (2004). Alexithymia and suicidal ideation: A 12-month follow-up study in a general population. Comprehensive Psychiatry, 45(5), 340-345.

https://doi.org/10.1016/j.comppsych.2004.06.008

42. Hintikka, J., Honkalampi, K., Lehtonen, J., \& Viinamäki, H. (2001). Are alexithymia and depression distinct or overlapping constructs?: A study in a general population. Comprehensive Psychiatry, 42(3), 234-239. https://doi.org/10.1053/comp.2001.23147

43. Hirsch, N., Hautekeete, M., \& Kochman, F. (2001). [Early maladaptive processes, depression and alexithymia in suicidal hospitalized adolescents]. Encephale, 61-70.

44. Honkalampi, K., Koivumaa-Honkanen, H., Tanskanen, A., Hintikka, J., Lehtonen, J., \& Viinamäki, H. (2001). Why do alexithymic features appear to be stable? A 12-month follow-up study of a general population. Psychotherapy and Psychosomatics, 70(5), 247-253.

https://doi.org/10.1159/000056262

45. Honkalampi, Kirsi, Hintikka, J., Saarinen, P., Lehtonen, J., \& Viinamäki, H. (2000). Is Alexithymia a Permanent Feature in Depressed Patients? Psychotherapy and Psychosomatics, 69(6), 303-308. https://doi.org/10.1159/000012412

46. Honkalampi, Kirsi, Hintikka, J., Tanskanen, A., Lehtonen, J., \& Viinamäki, H. (2000). Depression is strongly associated with alexithymia in the general population. Journal of Psychosomatic Research, 48(1), 99-104. https://doi.org/10.1016/S0022-3999(99)00083-5

47. Honkalampi, Kirsi, Koivumaa-Honkanen, H., Lehto, S. M., Hintikka, J., Haatainen, K., Rissanen, T., \& Viinamäki, H. (2010). Is alexithymia a risk factor for major depression, personality disorder, or alcohol use disorders? A prospective population-based study. Journal of Psychosomatic Research, 68(3), 269-273. https://doi.org/10.1016/j.jpsychores.2009.05.010

48. Huang, M.-F., Yeh, Y.-C., Tsang, H.-Y., \& Chen, C.-S. (2010). Alexithymia Associated With Bilateral Globus Pallidus Lesions After Carbon Monoxide Poisoning. The Kaohsiung Journal of Medical Sciences, 26(6), 333-336. https://doi.org/10.1016/S1607-551X(10)70048-6

49. Iancu, I., Dannon, P. N., Poreh, A., Lepkifker, E., \& Grunhaus, L. (2001). Alexithymia and suicidality in panic disorder. Comprehensive Psychiatry, 42(6), 477-481. https://doi.org/10.1053/comp.2001.27893 
50. Iancu, I., Horesh, N., Offer, D., Dannon, P. N., Lepkifker, E., \& Kotler, M. (1999). Alexithymia, Affect Intensity and Emotional Range in Suicidal Patients. Psychotherapy and Psychosomatics, 68(5), 276-280. https://doi.org/10.1159/000012344

51. Jørgensen, M. M., Zachariae, R., Skytthe, A., \& Kyvik, K. (2007). Genetic and Environmental Factors in Alexithymia: A Population-Based Study of 8,785 Danish Twin Pairs. Psychotherapy and Psychosomatics, 76(6), 369-375. https://doi.org/10.1159/000107565

52. Jouanne, C., Edel, Y., \& Carton, S. (2005). Déficits émotionnels chez des patients polytoxicomanes. Annales Médico-psychologiques, revue psychiatrique, 163(8), 625-630. https://doi.org/10.1016/j.amp.2004.05.013

53. Kauhanen, J., Kaplan, G. A., Cohen, R. D., Julkunen, J., \& Salonen, J. T. (1996). Alexithymia and risk of death in middle-aged men. Journal of Psychosomatic Research, 41(6), 541-549.

54. Kauhanen, J., Kaplan, G. A., Julkunen, J., Wilson, T. W., \& Salonen, J. T. (1993). Social factors in alexithymia. Comprehensive Psychiatry, 34(5), 330-335.

55. Kealy, D., Ogrodniczuk, J. S., Rice, S. M., \& Oliffe, J. L. (2018). Alexithymia, suicidal ideation and health-risk behaviours: A survey of Canadian men. International Journal of Psychiatry in Clinical Practice, 22(1), 77-79. https://doi.org/10.1080/13651501.2017.1324992

56. Keller, D. S., Carroll, K. M., Nich, C., \& Rounsaville, B. J. (1995). Alexithymia in Cocaine Abusers. The American Journal on Addictions, 4(3), 234-244. https://doi.org/10.3109/10550499509038108

57. Khantzian, E. J. (1997). The Self-Medication Hypothesis of Substance Use Disorders: A Reconsideration and Recent Applications. Harvard Review of Psychiatry, 4(5), 231-244. https://doi.org/10.3109/10673229709030550

58. Kim, H., Seo, J., Namkoong, K., Hwang, E. H., Sohn, S. Y., Kim, S. J., \& Kang, J. I. (2016). Alexithymia and perfectionism traits are associated with suicidal risk in patients with obsessive-compulsive disorder. Journal of Affective Disorders, 192, 50-55. https://doi.org/10.1016/j.jad.2015.12.018

59. Kokkonen, P., Karvonen, J. T., Veijola, J., Läksy, K., Jokelainen, J., Järvelin, M.-R., \& Joukamaa, M. (2001). Prevalence and sociodemographic correlates of alexithymia in a population sample of young adults. Comprehensive Psychiatry, 42(6), 471-476. https://doi.org/10.1053/comp.2001.27892

60. Koponen, S., Taiminen, T., Honkalampi, K., Joukamaa, M., Viinamäki, H., Kurki, T., Portin, R., Himanen, L., Isoniemi, H., Hinkka, S., \& Tenovuo, O. (2005). Alexithymia after traumatic brain injury: Its relation to magnetic resonance imaging findings and psychiatric disorders. Psychosomatic Medicine, 67(5), 807-812. https://doi.org/10.1097/01.psy.0000181278.92249.e5

61. Krystal, H. (1982). Alexithymia and the effectiveness of psychoanalytic treatment. International Journal of Psychoanalytic Psychotherapy, 9, 353-378.

62. Kubota, M., Miyata, J., Hirao, K., Fujiwara, H., Kawada, R., Fujimoto, S., Tanaka, Y., Sasamoto, A., Sawamoto, N., Fukuyama, H., Takahashi, H., \& Murai, T. (2011). Alexithymia and regional gray matter alterations in schizophrenia. Neuroscience Research, 70(2), 206-213. https://doi.org/10.1016/j.neures.2011.01.019 
63. Kubota, M., Miyata, J., Sasamoto, A., Kawada, R., Fujimoto, S., Tanaka, Y., Sawamoto, N., Fukuyama, H., Takahashi, H., \& Murai, T. (2012). Alexithymia and reduced white matter integrity in schizophrenia: A diffusion tensor imaging study on impaired emotional self-awareness. Schizophrenia Research, 141(2-3), 137-143. https://doi.org/10.1016/j.schres.2012.08.026

64. Law, K. C., Khazem, L. R., \& Anestis, M. D. (2015). The role of emotion dysregulation in suicide as considered through the ideation to action framework. Current Opinion in Psychology, 3, 30-35. https://doi.org/10.1016/j.copsyc.2015.01.014

65. Lecrubier, Y. (1998). Comorbidity in social anxiety disorder: Impact on disease burden and management. The Journal of Clinical Psychiatry, 59 Suppl 17, 33-38.

66. Lester, D. (1991). Alexithymia, Depression, and Suicidal Preoccupation. Perceptual and Motor Skills, 72(3), 1058-1058. https://doi.org/10.2466/pms.1991.72.3.1058

67. Leweke, F., Leichsenring, F., Kruse, J., \& Hermes, S. (2012). Is Alexithymia Associated with Specific Mental Disorders? Psychopathology, 45(1), 22-28. https://doi.org/10.1159/000325170

68. Lipowski, Z. J. (1990). Somatization and depression. Psychosomatics, 31(1), 13-21. https://doi.org/10.1016/S0033-3182(90)72212-8

69. Loas, G., Dalleau, E., Lecointe, H., \& Yon, V. (2016). Relationships between anhedonia, alexithymia, impulsivity, suicidal ideation, recent suicide attempt, C-reactive protein and serum lipid levels among 122 inpatients with mood or anxious disorders. Psychiatry Research, 246, 296-302. https://doi.org/10.1016/j.psychres.2016.09.056

70. Luminet, O., Bagby, R. M., \& Taylor, G. J. (2001). An evaluation of the absolute and relative stability of alexithymia in patients with major depression. Psychotherapy and Psychosomatics, 70(5), 254-260. https://doi.org/10.1159/000056263

71. Luminet, Olivier, Rokbani, L., Ogez, D., \& Jadoulle, V. (2007). An evaluation of the absolute and relative stability of alexithymia in women with breast cancer. Journal of Psychosomatic Research, 62(6), 641-648.

72. Mann, J. J. (2002). A current perspective of suicide and attempted suicide. Annals of Internal Medicine, 136(4), 302-311.

73. Marasco, V., De Berardis, D., Serroni, N., Campanella, D., Acciavatti, T., Caltabiano, M., Olivieri, L., Rapini, G., Cicconetti, A., Carano, A., La Rovere, R., Di lorio, G., Moschetta, F. S., \& Di Giannantonio, M. (2011). [Alexithymia and suicide risk among patients with schizophrenia: Preliminary findings of a cross-sectional study]. Rivista Di Psichiatria, 46(1), 31-37.

74. Marchesi, C., Brusamonti, E., \& Maggini, C. (2000). Are alexithymia, depression, and anxiety distinct constructs in affective disorders? Journal of Psychosomatic Research, 49(1), 43-49.

75. Marchesi, Carlo, Ossola, P., Tonna, M., \& De Panfilis, C. (2014). The TAS-20 more likely measures negative affects rather than alexithymia itself in patients with major depression, panic disorder, eating disorders and substance use disorders. Comprehensive Psychiatry, 55(4), 972-978. https://doi.org/10.1016/j.comppsych.2013.12.008 
76. Messina, A., Beadle, J. N., \& Paradiso, S. (2014). Towards a classification of alexithymia: Primary, secondary and organic. 12.

77. Mikolajczak, M., \& Luminet, O. (2006). Is alexithymia affected by situational stress or is it a stable trait related to emotion regulation? Personality and Individual Differences, 40(7), 1399-1408. https://doi.org/10.1016/j.paid.2005.10.020

78. Nehra, D. K., Kumar, P., Sharma, V., \& Nehra, S. (2013). Alexithymia and emotional intelligence among people with cannabis dependence and healthy control: A comparative study. 9.

79. Orbach, I., Bar-Joseph, H., \& Dror, N. (1990). Styles of Problem Solving in Suicidal Individuals. Suicide and Life-Threatening Behavior, 20(1), 56-64. https://doi.org/10.1111/j.1943-278X.1990.tb00653.x

80. Oskis, A., Clow, A., Hucklebridge, F., Bifulco, A., Jacobs, C., \& Loveday, C. (2013). Understanding alexithymia in female adolescents: The role of attachment style. Personality and Individual Differences, 54(1), 97-102. https://doi.org/10.1016/j.paid.2012.08.023

81. Oyefeso, A., Brown, S., Chiang, Y., \& Clancy, C. (2008). Self-injurious behaviour, traumatic life events and alexithymia among treatment-seeking opiate addicts: Prevalence, pattern and correlates. Drug and Alcohol Dependence, 98(3), 227-234. https://doi.org/10.1016/j.drugalcdep.2008.06.004

82. Parker, J. D. A., Bagby, R. M., \& Taylor, G. J. (1991). Alexithymia and depression: Distinct or overlapping constructs? Comprehensive Psychiatry, 32(5), 387-394. https://doi.org/10.1016/0010440X(91)90015-5

83. Parker, J. D. A., Bagby, R. M., Taylor, G. J., Endler, N. S., \& Schmitz, P. (1993). Factorial validity of the 20-item Toronto Alexithymia Scale. European Journal of Personality, 7(4), 221-232. https://doi.org/10.1002/per.2410070403

84. Parolin, M., Simonelli, A., Mapelli, D., Sacco, M., \& Cristofalo, P. (2016). Parental Substance Abuse As an Early Traumatic Event. Preliminary Findings on Neuropsychological and Personality Functioning in Young Drug Addicts Exposed to Drugs Early. Frontiers in Psychology, 7. https://doi.org/10.3389/fpsyg.2016.00887

85. Plutchik, R., \& Van Praag, H. (1989). The measurement of suicidality, aggressivity and impulsivity. Progress in Neuro-Psychopharmacology and Biological Psychiatry, 13, S23-S34. https://doi.org/10.1016/0278-5846(89)90107-3

86. Posner, K., Brown, G. K., Stanley, B., Brent, D. A., Yershova, K. V., Oquendo, M. A., Currier, G. W., Melvin, G. A., Greenhill, L., Shen, S., \& Mann, J. J. (2011). The Columbia-Suicide Severity Rating Scale: Initial Validity and Internal Consistency Findings From Three Multisite Studies With Adolescents and Adults. The American Journal of Psychiatry, 168(12), 1266-1277. https://doi.org/10.1176/appi.ajp.2011.10111704

87. Posse, M., \& Hällström, T. (1998). Depressive disorders among somatizing patients in primary health care. Acta Psychiatrica Scandinavica, 98(3), 187-192. https://doi.org/10.1111/j.1600-

0447.1998.tb10065.x

88. Preuss, U. W., Schuckit, M. A., Smith, T. L., Danko, G. P., Buckman, K., Bierut, L., Bucholz, K. K., Hesselbrock, M. N., Hesselbrock, V. M., \& Reich, T. (2002). Comparison of 3190 Alcohol-Dependent 
Individuals With and Without Suicide Attempts. Alcoholism: Clinical and Experimental Research, 26(4), 471-477. https://doi.org/10.1111/j.1530-0277.2002.tb02563.x

89. Rieffe, C., Oosterveld, P., \& Terwogt, M. M. (2006). An alexithymia questionnaire for children: Factorial and concurrent validation results. Personality and Individual Differences, 40(1), 123-133. https://doi.org/10.1016/j.paid.2005.05.013

90. Roy, A. (2003). Characteristics of drug addicts who attempt suicide. Psychiatry Research, 121(1), 99103. https://doi.org/10.1016/S0165-1781(03)00206-3

91. Rybakowski, J., Ziółkowski, M., Zasadzka, T., \& Brzeziński, R. (1988). High prevalence of alexithymia in male patients with alcohol dependence. Drug and Alcohol Dependence, 21(2), 133-136.

92. Saarijärvi, S., Salminen, J. K., \& Toikka, T. (2006). Temporal Stability of Alexithymia Over a Five-Year Period in Outpatients with Major Depression. Psychotherapy and Psychosomatics, 75(2), 107-112. https://doi.org/10.1159/000090895

93. Saarijärvi, S, Salminen, J. K., \& Toikka, T. B. (2001). Alexithymia and depression. Journal of Psychosomatic Research, 51(6), 729-733. https://doi.org/10.1016/S0022-3999(01)00257-4

94. Saarijärvi, Simo, Salminen, J. K., Tamminen, T., \& Äärelä, E. (1993). Alexithymia in psychiatric consultation-liaison patients. General Hospital Psychiatry, 15(5), 330-333. https://doi.org/10.1016/0163-8343(93)90026-K

95. Sakuraba, S., Kubo, M., Komoda, T., \& Yamana, J.-I. (2005). Suicidal ideation and alexithymia in patients with alcoholism: A pilot study. Substance Use \& Misuse, 40(6), 823-830.

96. Salminen, J. K., Saarijärvi, S., Ääirelä, E., \& Tamminen, T. (1994). Alexithymia-state or trait? One-year follow- up study of general hospital psychiatric consultation out-patients. Journal of Psychosomatic Research, 38(7), 681-685. https://doi.org/10.1016/0022-3999(94)90020-5

97. Salminen, J. K., Saarijärvi, S., Äärelä, E., Toikka, T., \& Kauhanen, J. (1999). Prevalence of alexithymia and its association with sociodemographic variables in the general population of finland. Journal of Psychosomatic Research, 46(1), 75-82. https://doi.org/10.1016/S0022-3999(98)00053-1

98. Sayar, K., Kirmayer, L. J., \& Taillefer, S. S. (2003). Predictors of somatic symptoms in depressive disorder. General Hospital Psychiatry, 25(2), 108-114.

99. Serafini, G., Gonda, X., Canepa, G., Pompili, M., Rihmer, Z., Amore, M., \& Engel-Yeger, B. (2017). Extreme sensory processing patterns show a complex association with depression, and impulsivity, alexithymia, and hopelessness. Journal of Affective Disorders, 210, 249-257. https://doi.org/10.1016/j.jad.2016.12.019

100. Sifneos, P. E. (1973). The prevalence of "alexithymic" characteristics in psychosomatic patients. Psychotherapy and Psychosomatics, 22(2-6), 255-262. https://doi.org/10.1159/000286529

101. Spielberger, C. D., Gorsuch, R. L., \& Lushene, R. E. (1970). Manual for the State-Trait Anxiety Inventory. http://ubir.buffalo.edu/xmlui/handle/10477/2895

102. Stewart, S. H., Zvolensky, M. J., \& Eifert, G. H. (2002). The Relations of Anxiety Sensitivity, Experiential Avoidance, and Alexithymic Coping to Young Adults' Motivations for Drinking. Behavior Modification, 26(2), 274-296. https://doi.org/10.1177/0145445502026002007 
103. Taiminen, T. J., Saarijärvi, S., Helenius, H., Keskinen, A., \& Korpilahti, T. (1996). Alexithymia in suicide attempters. Acta Psychiatrica Scandinavica, 93(3), 195-198. https://doi.org/10.1111/j.16000447.1996.tb10631.x

104. Taylor, G. J. (2000). Recent Developments in Alexithymia Theory and Research. The Canadian Journal of Psychiatry, 45(2), 134-142. https://doi.org/10.1177/070674370004500203

105. Taylor, G. J., \& Bagby, R. M. (2004). New Trends in Alexithymia Research. Psychotherapy and Psychosomatics, 73(2), 68-77. https://doi.org/10.1159/000075537

106. Taylor, G. J., Bagby, R. M., \& Parker, J. D. A. (1997). Disorders of affect regulation: Alexithymia in medical and psychiatric illness. Cambridge University Press.

https://doi.org/10.1017/CB09780511526831

107. Taylor, G. J., Bagby, R. M., \& Parker, J. D. A. (2003). The 20-Item Toronto Alexithymia Scale. IV. Reliability and factorial validity in different languages and cultures. Journal of Psychosomatic Research, 55(3), 277-283.

108. Tolmunen, T., Heliste, M., Lehto, S. M., Hintikka, J., Honkalampi, K., \& Kauhanen, J. (2011). Stability of alexithymia in the general population: An 11-year follow-up. Comprehensive Psychiatry, 52(5), 536541. https://doi.org/10.1016/j.comppsych.2010.09.007

109. Torrado, M. V., Ouakinin, S. S., \& Bacelar-Nicolau, L. (2013). Alexithymia, Emotional Awareness and Perceived Dysfunctional Parental Behaviors in Heroin Dependents. International Journal of Mental Health and Addiction, 11(6), 703-718. https://doi.org/10.1007/s11469-013-9448-z

110. Troisi, A., Pasini, A., Saracco, M., \& Spalletta, G. (1998). Psychiatric symptoms in male cannabis users not using other illicit drugs. Addiction (Abingdon, England), 93(4), 487-492.

111. Verrocchio, M. C., Conti, C. M., \& Fulcheri, M. (2010). Deliberate self-harm in substance-dependent patients and relationship with alexithymia and personality disorders: A case-control study. Journal of Biological Regulators and Homeostatic Agents.

112. Voss, W. D., Kaufman, E., O’Connor, S. S., Comtois, K. A., Connor, K. R., \& Ries, R. K. (2013). Preventing Addiction Related Suicide: A Pilot Study. Journal of Substance Abuse Treatment, 44(5), 565-569. https://doi.org/10.1016/j.jsat.2012.10.006

113. Zeitlin, S. B., McNally, R. J., \& Cassiday, K. L. (1993). Alexithymia in victims of sexual assault: An effect of repeated traumatization? The American Journal of Psychiatry, 150(4), 661-663. https://doi.org/10.1176/ajp.150.4.661

114. Ziółkowski, M., Gruss, T., \& Rybakowski, J. K. (1995). Does Alexithymia in Male Alcoholics Constitute a Negative Factor for Maintaining Abstinence? Psychotherapy and Psychosomatics, 63(3-4), 169173. https://doi.org/10.1159/000288955

115. Zlotnick, C., Shea, M. T., Pearlstein, T., Simpson, E., Costello, E., \& Begin, A. (1996). The relationship between dissociative symptoms, alexithymia, impulsivity, sexual abuse, and self-mutilation. Comprehensive Psychiatry, 37(1), 12-16. https://doi.org/10.1016/S0010-440X(96)90044-9 